\title{
Reversibility of enzymatic reactions might limit biotransformation of organic micropollutants
}

Lorena Gonzalez-Gil $^{\text {a*}}$, Marta Carballa ${ }^{\text {a }}$, Philippe F.-X. Corvini ${ }^{\text {b }}$, Juan M. Lema ${ }^{\text {a }}$

${ }^{a}$ Department of Chemical Engineering, School of Engineering, Universidade de Santiago

de Compostela, Rúa Lope Gómez de Marzoa, E-15782 Santiago de Compostela, Spain

${ }^{\mathrm{b}}$ Institute for Ecopreneurship, School of Life Sciences, University of Applied Sciences and Arts Northwestern Switzerland, 4132 Muttenz, Switzerland

*Corresponding Author

E-mail addresses: lorena.gonzalez@usc.es, marta.carballa@usc.es,

philippe.corvini@fhnw.ch,juan.lema@usc.es 


\section{Highlights}

The causes behind the incomplete biotransformation of micropollutants remain unknown.

Reversibility of enzymatic reactions were investigated in vitro assays.

Bisphenol A might be phosphorylated by kinase enzymes in anaerobic processes.

Acetate kinase and hexokinase transform bisphenol A in a reversible way.

Reversible reactions might lead to an equilibrium impeding a total biotransformation.

\section{Graphical abstract}

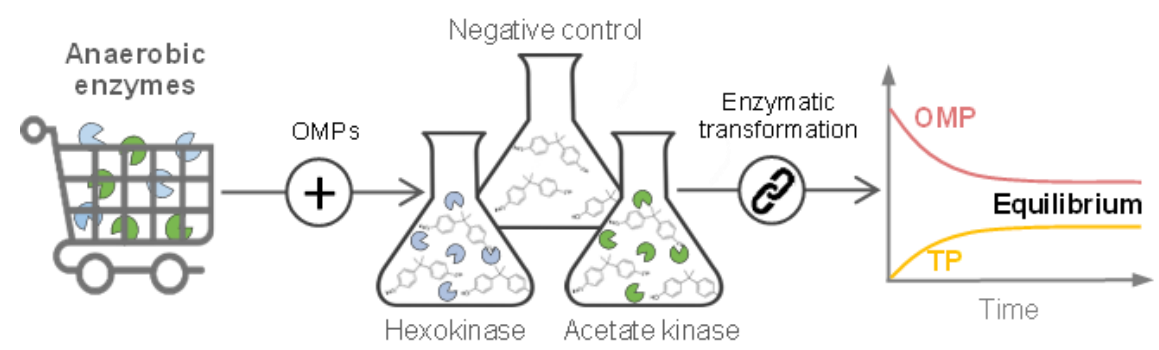




\begin{abstract}
Biotransformation of many organic micropollutants (OMPs) in sewage treatment plants is incomplete leading to their release into the environment. Recent findings suggest that thermodynamic aspects of the reaction as chemical equilibrium limit biotransformation, while kinetic parameters have a lower influence. Reversibility of enzymatic reactions might result in a chemical equilibrium between the OMP and the transformation product, thus impeding a total removal of the compound. To the best of our knowledge, no study has focused on proving the reversible action of enzymes towards OMPs so far. Therefore, we aimed at demonstrating this hypothesis through in vitro assays with bisphenol A (BPA) in the presence of kinase enzymes, namely acetate kinase and hexokinase, which are key enzymes in anaerobic processes. Results suggest that BPA is phosphorylated by acetate kinase and hexokinase in the presence of ATP (adenosine 5-triphosphate), but when the concentration of this co-substrate decreases and the enzymes loss their activity, the backward reaction occurs, revealing a reversible biotransformation mechanism. This information is particularly relevant to address new removal strategies, which up to now were mainly focused on modifying the kinetic parameters of the reaction.
\end{abstract}

Keywords: anaerobic digestion; bisphenol A; chemical equilibrium; kinases; phosphorylation; sewage treatment plant. 


\section{INTRODUCTION}

Biological systems can transform a wide variety of organic micropollutants (OMPs); actually, biotransformation is a key removal mechanism of OMPs in sewage treatment plants (STPs). However, most compounds are not fully biotransformed and concentration kinetic plateaus are reported in a wide variety of aerobic (Blair et al., 2015; FernandezFontaina et al., 2014; Gulde et al., 2018; Xue et al., 2010) and anaerobic (Gonzalez-Gil et al., 2018b; Xue et al., 2010) reactors operating in batch or continuously. Since no substrate limitations are expected in steady-state continuous reactors, a decrease of the metabolic activity and thus of the cometabolic transformation of OMPs is excluded. Yet, several hypotheses can be postulated to explain this behavior. It was recently proved through a modelling approach that thermodynamic constraints (i.e., reversibility of the biological reactions and/or sequestration of OMPs) rather than kinetic limitations (hydraulic retention time, OMPs concentration, inhibition by the transformation product (TP) and biotransformation rate constant) are responsible for the incomplete biotransformation of several OMPs in anaerobic systems (Gonzalez-Gil et al., 2018a). Although there are some experimental evidences of reversible reactions affecting OMPs, such as the conversion of sulfamethoxazole (SMX) into acetyl-SMX (Achermann et al., 2018) and the phosphorylation of different bisphenols (Zühlke et al., 2016), so far no study was focused on demonstrating the reversibility of the enzymatic transformation of OMPs.

Kinases are a class of enzymes (EC 2.7.-) that catalyze the transfer of phosphate groups from high-energy phosphate-donating molecules (e.g., adenosine 5-triphosphate, ATP) to specific substrates. This reaction, known as phosphorylation, is reversible 
(dephosphorylation). Kinases are key enzymes in STPs; for instance, they catalyze the first step of glycolysis and acetate methanization (Figure 1) during anaerobic digestion. Hexokinase (HK, EC 2.7.1.1) was found in acidogenic bacteria (i.e., Clostridia, Alphaproteobacteria and Bacteroidetes) (Canback et al., 2002; Guo et al., 2015; Hylemon et al., 1977; Kotze, 1969) and is mainly responsible for glucose phosphorylation during glycolysis (Figure 1), although it can also phosphorylate other hexose substrates (BRENDA The Comprehensive Enzyme Information System; Cárdenas et al., 1998). Acetate kinase (AK, EC 2.7.2.1) is involved in the last acetogenic reaction (dephosphorylation of acetyl phosphate to acetate; Figure 1) in fermentative bacteria (Ferry, 2011). Moreover, this enzyme catalyzes the reverse reaction (phosphorylation of acetate to acetyl phosphate; Figure 1) in Methanosarcina species, that is, the first step in acetoclastic methanogenesis (Gorrell and Ferry, 2007). It was demonstrated that AK can transform OMPs with carboxyl (i.e., diclofenac, naproxen and ibuprofen) and hydroxyl groups (i.e., bisphenol A (BPA), triclosan, octylphenol and nonylphenol) (Gonzalez-Gil et al., 2017). Therefore, both HK and AK are key enzymes in anaerobic processes and might be candidates that catalyze reversible transformation reactions of OMPs, in particular of BPA, whose phosphorylated TP was already detected in the presence of bacterial species from sewage sludge (Zühlke et al., 2016). Based on these previous results and taking into account its widespread presence in the environment and its harmful endocrine disrupting activity (Rubin, 2011), BPA seems to be an appropriate OMP to further investigate its enzymatic transformation mechanisms. 


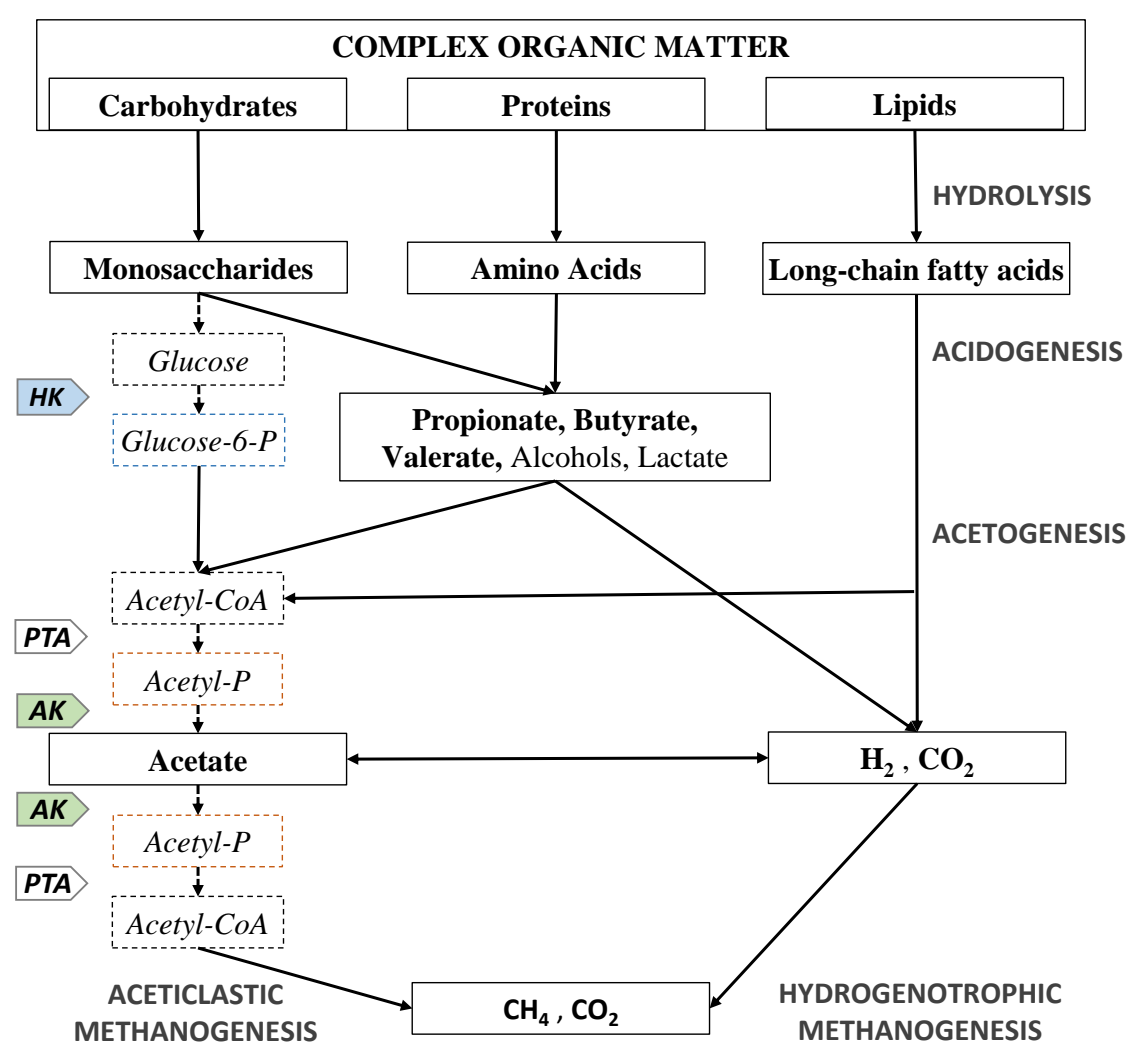

Figure 1. Schematic representation of the steps of anaerobic digestion, including the roles of the enzymes hexokinase (HK), acetate kinase (AK) and phosphotransacetylase (PTA).

The objective of this study was to demonstrate that the enzymatic transformations of OMPs might occur in a reversible way, which could lead to a chemical equilibrium between the parent compound and the TP, and thus to removal efficiencies below 100\%. In particular, in vitro assays with $\mathrm{HK}$ and AK enzymes were performed in the presence of BPA, which was selected as a model compound to prove this behavior. To the best of our knowledge, this is the first attempt to clarify the role of enzymes on the reversible biotransformation of OMPs. 


\section{MATERIALS AND METHODS}

\subsection{Commercial enzymes and enzymatic activities}

\subsubsection{Acetate kinase}

AK catalyzes the reversible transfer of the $\Upsilon$-phosphoryl group from ATP to acetate (Reaction 1) (Gorrell and Ferry, 2007). AK from Methanosarcina thermophila was preferred for this study because Methanosarcina species are key organisms in anaerobic digestion (De Vrieze et al., 2012) and their action towards OMPs was already demonstrated in previous experiments (Gonzalez-Gil et al., 2017). However, AK from M. thermophila was anymore available at Sigma-Aldrich; hence, AK from E. coli was purchased as lyophilized powder $(\geq 150 \mathrm{U} / \mathrm{mg}$ protein (biuret)). One unit (U) of this enzyme phosphorylates $1.0 \mu \mathrm{mol}$ of acetate to acetyl phosphate per min at $\mathrm{pH} 7.6$ and $25{ }^{\circ} \mathrm{C}$.

Acetate $+\mathrm{ATP} \stackrel{A K}{\longleftrightarrow}$ Acetyl-P + ADP $\quad$ (Reaction 1)

The hydroxamate assay described by Gonzalez-Gil et al. (2017) was scaled down to be performed in 96-well plates with $40 \mu \mathrm{L}$ of sample. The calibration curve (Figure S1) was prepared with a standard of lithium potassium acetyl phosphate purchased from SigmaAldrich. Plates were measured spectrophotometrically in a BioTek Synergy 2 plate reader (BioTek Instruments Inc., USA). Preliminary activity assays were carried out to estimate the amount of enzyme that should be added in AK experiments with BPA. 


\subsubsection{Hexokinase}

Hexokinases catalyze the ATP-dependent phosphorylation of several hexoses to hexose-6-

phosphate. Depending on the organism, hexokinases present different kinetic and molecular characteristics (Cárdenas et al., 1998). Although HK from bacteria would be preferred in this study to simulate enzymatic reactions during anaerobic digestion, the only HK commercially available was the produced by the yeast Saccharomyces cerevisiae. It was purchased from Sigma-Aldrich in suspension form ( $3.2 \mathrm{M}$ ammonium sulfate, $\mathrm{pH} \approx 6.5$ ) with a specific activity $>450 \mathrm{U} / \mathrm{mg}$ protein $\left(\right.$ at $25{ }^{\circ} \mathrm{C}$ and $\mathrm{pH} 7.6$ with D-glucose and ATP as substrates).

HK activity was measured by the hexokinase colorimetric assay kit (Sigma-Aldrich). The procedure is detailed in the corresponding technical notice of Sigma and summarized in Supplementary Data (Section II). In brief, HK phosphorylates glucose into glucose-6phosphate. The latter is oxidized by glucose-6-phosphate dehydrogenase to form NADH, which generates a colored product $(450 \mathrm{~nm})$ proportional to the $\mathrm{HK}$ activity. Thus, one unit of HK corresponds to the amount of enzyme that generates $1.0 \mu$ mole of NADH per minute at $\mathrm{pH} 8.0$ and room temperature. Preliminary activity assays were carried out to estimate the amount of enzyme that should be added in HK experiments with BPA.

\subsection{Enzymatic experiments with radiolabeled BPA}

Radiolabeled BPA $\left({ }^{14} \mathrm{C}-\mathrm{BPA}\right.$, phenol ring $\left.{ }^{14} \mathrm{C}(\mathrm{U})\right)$ was purchased from Hartmann Analytic (Germany) with a specific radioactivity of $3.92 \times 10^{9} \mathrm{~Bq} / \mathrm{mmol}$, a radiochemical purity of $98.8 \%$ and a concentration of $218.58 \mu \mathrm{g} / \mathrm{mL}$ in ethanol. 


\subsubsection{Experiments with $A K$}

Enzymatic experiments with AK were run in triplicate $(\mathrm{n}=3)$ at similar conditions as the experiments previously performed by Gonzalez-Gil et al. (2017) $\left(25^{\circ} \mathrm{C}, \mathrm{pH} 7.6,145 \mathrm{mM}\right.$ of Tris- $\mathrm{HCl}, 10 \mathrm{mM}$ of $\mathrm{MgCl}_{2} \cdot 6 \mathrm{H}_{2} \mathrm{O}$, and $705 \mathrm{mM}$ of hydroxylamine hydrochloride). Acetate was not supplied. The initial concentration of ATP was $10 \mathrm{mM}$ (in excess), the initial activity of AK from E. coli was set at $50 \mathrm{U} / \mathrm{L}$, and the concentration of BPA was $10 \mu \mathrm{M}\left(4 \mu \mathrm{M}\right.$ of ${ }^{14} \mathrm{C}-\mathrm{BPA}$ and $6 \mu \mathrm{M}$ of BPA, in total $\left.2.3 \mathrm{mg} / \mathrm{L}\right)$. Higher concentrations of BPA and AK than those used by Gonzalez-Gil et al. (2017) were set in order to facilitate the detection of possible TPs, but no changes in the enzymatic transformation mechanisms (i.e., reversibility of reactions) are expected. The final volume of the assay was $10 \mathrm{~mL}$. Negative controls (without AK) were also conducted in triplicate. Moreover, a blank without BPA was performed to test the possible inhibitory effect of this compound on the AK activity and to identify false TP peaks due to background signals. $100 \mu \mathrm{L}$ samples were withdrawn at different reaction times and mixed with $50 \mu \mathrm{L}$ of trichloroacetic acid to stop the reaction prior to HPLC or LC-MS/MS analyses. AK activity (see section 2.1.1), $\mathrm{pH}$ and temperature were also monitored along time.

\subsubsection{Experiments with $\mathrm{HK}$}

The action of HK on BPA was tested in assays with a similar experimental layout as those performed with AK. The assays were conducted at $25^{\circ} \mathrm{C}, \mathrm{pH} 7.6$, in $100 \mathrm{mM}$ phosphate buffer with $6.5 \mathrm{mM}$ of $\mathrm{MgCl}_{2} \cdot 6 \mathrm{H}_{2} \mathrm{O}$ (Fromm et al., 1964; Souza et al., 2002), $10 \mathrm{mM}$ of ATP (excess) and $10 \mu \mathrm{M}(2.3 \mathrm{mg} / \mathrm{L})$ of BPA $\left(4 \mu \mathrm{M}\right.$ of ${ }^{14} \mathrm{C}-\mathrm{BPA}$ and $6 \mu \mathrm{M}$ of BPA). Glucose was not supplied. HK was added to achieve an initial activity of $50 \mathrm{U} / \mathrm{L}, 5$-times 
above the estimated maximum activity in a typical anaerobic digester (assuming that acetate is exclusively produced from glucose). Under these conditions, the equilibrium should be displaced to the forward reaction (phosphorylation of glucose) (Fromm et al., 1964). These assays were conducted in triplicate $(\mathrm{n}=3)$ with a final volume of $5 \mathrm{~mL}$. Besides, triplicated negative controls (without enzyme) and a blank (without BPA) were performed. Samples of $80 \mu \mathrm{L}$ were withdrawn at different times and mixed with $40 \mu \mathrm{L}$ of trichloroacetic acid to stop the enzymatic reaction prior to HPLC or LC-MS/MS analyses. Enzymatic activities (5-10 $\mu \mathrm{L}), \mathrm{pH}$ and temperature were also monitored along time.

\subsection{Radiolabeled BPA analysis}

In order to determine the concentration of ${ }^{14} \mathrm{C}$-BPA, HPLC analyses were carried out using Agilent Tech. HPLC 1200 Series coupled to a radioisotope detector Ramona Star (Raytest, Germany). A Zorbax SB C18 (3.0 x $150 \mathrm{~mm}$, particle size $3.5 \mu \mathrm{m})$ was thermostated at 30 ${ }^{\circ} \mathrm{C}$ and 150 bar and the flow-rate was set at $0.5 \mathrm{~mL} / \mathrm{min}$. The mobile phase consisted of 20 $\mathrm{mM}$ ammonium formate without $\mathrm{pH}$ adjustment (solvent $\mathrm{A}$ ) and acetonitrile (Ultra gradient HPLC grade, J.T Baker) (solvent B). A linear elution gradient from 10 to $80 \%$ B was applied for the 10 first minutes and then $80 \%$ B was maintained for 10 minutes. Sample aliquots of $65 \mu \mathrm{L}$ were immediately injected in the HPLC to avoid back-transformation of BPA.

\subsection{Statistical analysis}

All of the enzymatic assays with BPA and the negative controls (without enzyme) were conducted in triplicate $(n=3)$. The variance homogeneity of data was determined by applying Levene's test. Significant differences between the enzymatic assay and the 
corresponding negative control were assessed by Student's $t$-test. All of the statistical tests were performed at a 5\% significance level by using IBM SPSS statistics software 22.0.

\section{RESULTS AND DISCUSSION}

\subsection{Reversible transformation of BPA by AK}

Figure 2 suggests that the biotransformation of BPA by AK is reversible. $3 \mathrm{~h}$ after starting the reaction in the presence of $\mathrm{AK}$, the concentration of ${ }^{14} \mathrm{C}$-BPA significantly decreased with respect to the negative control (Student's $t$-test; $\mathrm{p} \leq 0.05$ ). However, as reaction time elapsed, the AK activity decreased (Figure 2) and concomitantly the BPA transformation went backwards. After $46 \mathrm{~h}$, a pulse of AK (75 U/L) and ATP (10 mM) was added ( $2 \%$ of the initial assay volume). As a result, the AK activity rose and again the concentration of BPA significantly (Student's $t$-test; $\mathrm{p} \leq 0.05$ ) decreased with respect to the negative control until the AK activity fell again (after $160 \mathrm{~h}$ ). To explain this behavior, the phosphorylation of acetate by AK (Reaction 1) is taken as a reference. Rose et al. (1954) proved that acetate phosphorylation is reversible and the backwards reaction (dephosphorylation of acetyl phosphate, Reaction 1) is favored kinetically and thermodynamically. Thereby, when equilibrium is attained, the conversion of acetate into the phosphorylated product is very low. This equilibrium could be shifted by increasing the concentration of reagents (i.e., ATP) or decreasing the concentration of products (if consumed in later reactions), but not by the presence of a catalyst (i.e., AK), which only increases the transformation rate until equilibrium is achieved. Therefore, at the beginning of the assay with BPA and after the second pulse of ATP and AK, the excessive concentration of ATP and the high AK activity make possible to detect a significant decrease of BPA in few hours (Figure 2). However, 
since AK losses its activity with time (Figure 2) and ATP concentration may decrease because of its poor stability in neutral solutions (it is hydrolyzed to ADP or even AMP, Sigma Product Information), the spontaneous dephosphorylation of BPA might be favored.

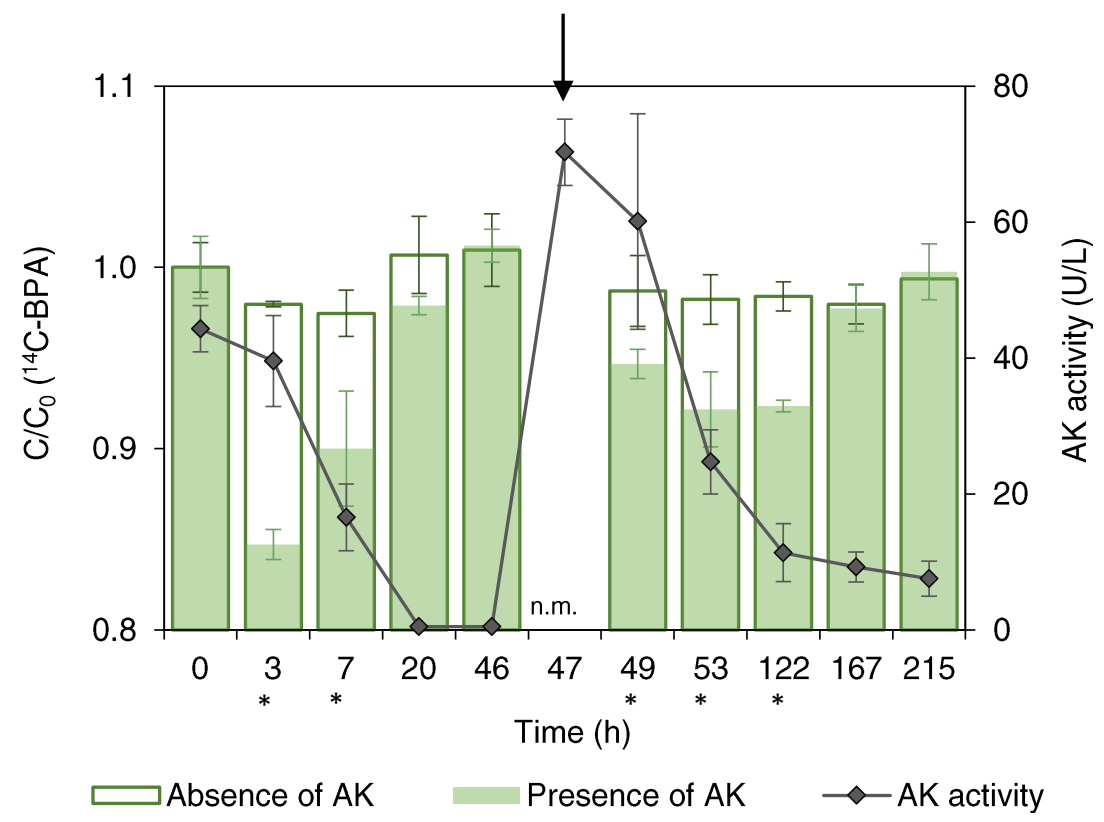

Figure 2. Comparison of the relative concentration of ${ }^{14} \mathrm{C}-\mathrm{BPA}$ in negative controls without AK (white bars, $n=3$ ) with respect to the assays with AK (green bars, $n=3$ ). The asterisks highlight significant differences (Student's $t$ test; $p \leq 0.05$ ) between both concentrations due to the enzymatic action. The AK activity (diamonds, $\mathrm{n}=3$ ) during the assay is plotted on the secondary y-axis. The arrow indicates the second addition of ATP and AK. n.m. stands for not measured.

The reversible pattern observed in Figure 2 is supported by the work of Zühlke et al. (2016), who first reported the formation of phosphate conjugates with BPA and other bisphenols in microorganisms, namely Bacillus amyloliquefaciens isolated from a STP. According to the authors, phosphorylated bisphenols were considerably less toxic and 
estrogenic than the parent compound. They speculate that dephosphorylation might have occurred due to cell lysis, but no evidences were provided. Since AK is present in $B$. amyloliquefaciens (Feng et al., 2017), we hypothesize that this enzyme could have been involved in the reported reversible phosphorylation of bisphenols. Apart from $B$. amyloliquefaciens, few microorganisms have shown the ability to form phosphate conjugates so far. Under anoxic conditions, the denitrifying bacteria Pseudomonas sp. (Lack and Fuchs, 1994) and Thauera aromatica (Schmeling et al., 2004) phosphorylate phenol as a first step of phenol degradation. The novel enzyme phenylphosphate synthase catalyzes this reaction in T. aromatica (Schmeling et al., 2004) and its presence in anaerobic digestion and role in the phosphorylation of OMPs cannot be ruled out.

\subsection{Reversible transformation of BPA by HK}

Results (Figure 3) prove that HK was able to slightly but significantly (Student's $t$-test; $\mathrm{p} \leq$ 0.05) decrease the concentration of ${ }^{14} \mathrm{C}-\mathrm{BPA}$ compared to the negative control after $4 \mathrm{~h}$ of reaction time. Similarly to the experiments with AK, the loss of HK activity (Figure 3) and the possible decrease in the ATP concentration could explain the recovery of the initial BPA concentration observed after $21 \mathrm{~h}$. Thus, at this time, a pulse of HK (50 U/L) and ATP $(10 \mathrm{mM})$ was added (4\% of the initial assay volume). Consequently, the enzymatic activity rose and again the BPA concentration significantly decreased (Student's $t$-test; $\mathrm{p} \leq 0.05$ ) until the end of the experiment (Figure 3). Besides, a slight reduction in the BPA concentration of the negative controls after $21 \mathrm{~h}$ was observed due to the volume increase (4\%) of the assays by the pulse. This difference is lower in the experiments with AK (Figure 2) because the ATP and AK pulse only represents a 2\% of the initial assay volume. 
The transformation of BPA by HK also seems to be reversible, since it followed a similar pattern as the assays with AK. However, during the second step of the assay (after the second pulse of ATP and $\mathrm{HK}$ ), a recovery of the BPA concentration was not observed, probably because of the much lower reaction time (52 h) than that in the AK assays (215 h), which likely was not enough to have a significant decrease in the ATP concentration that shifted the equilibrium.

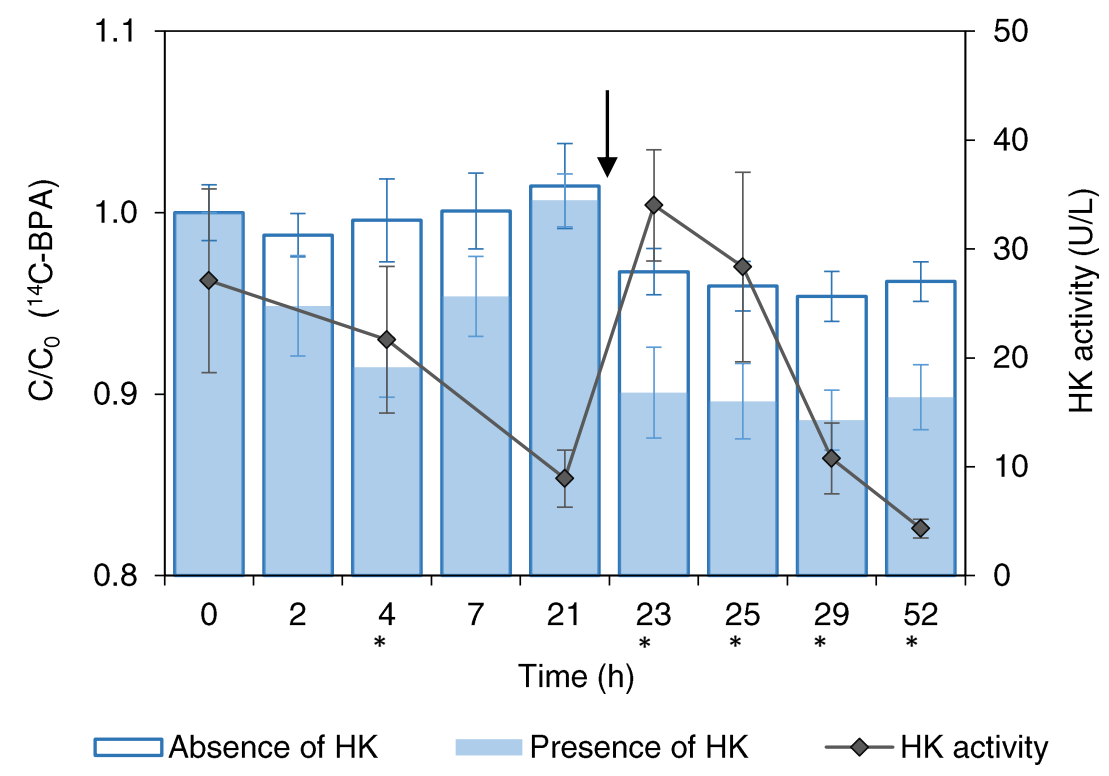

Figure 3. Comparison of the relative concentration of ${ }^{14} \mathrm{C}-\mathrm{BPA}$ in negative controls without HK (white bars, $n=3$ ) with respect to the assays with HK (blue bars, $n=3$ ). The asterisks highlight significant differences (Student's t test; $\mathrm{p} \leq 0.05$ ) between both concentrations due to the enzymatic action. The HK activity (diamonds, $\mathrm{n}=3$ ) during the assay is plotted on the secondary y-axis. The arrow indicates the second addition of ATP and HK.

Finally, it should be noticed that the maximum removal efficiencies achieved in the in vitro experiments with AK (Figure 2) and HK (Figure 3) are lower than the reported values in 
some anaerobic reactors (40-80\%) (Gonzalez-Gil et al., 2018b; Samaras et al., 2014;

Wijekoon et al., 2015). This is an expected result, since many other enzymes are involved in anaerobic processes that could also participate in the biotransformation of BPA.

Moreover, the substrate affinities and specificities of the purified AK from E. coli and HK from $S$. cerevisiae might differ from the real enzymes present in the anaerobic reactors. For instance, AK from E. coli is more specific than AK from M. thermophila (Allen et al., 1964; Nakajima et al., 1978; Rose et al., 1954), which could explain why the biotransformation degree in these experiments was lower than that previously achieved by Gonzalez-Gil et al. (2017).

\subsection{Reversible cometabolic pathway of BPA}

A cometabolic transformation can only occur if the OMPs have a chemical structure compatible with the active site of the enzymes. Therefore, AK and HK, which are key enzymes in anaerobic processes (Canback et al., 2002; Gorrell and Ferry, 2007; Hylemon et

al., 1977; Kotze, 1969), could cometabolically phosphorylate a hydroxyl group of BPA in a reversible way (Figure 4), as they do with their metabolic substrates (i.e., acetate and glucose, respectively). Despite being not possible to identify the resulting phosphorylated BPA in this study, Zühlke et al. (2016) have measured this TP and have proved its reversible conversion into BPA by B. amyloliquefaciens. These authors did not find the causes behind the reversibility of this reaction, but the presence of $\mathrm{AK}$ in this bacteria (Feng et al., 2017) might explain it supporting our findings. 

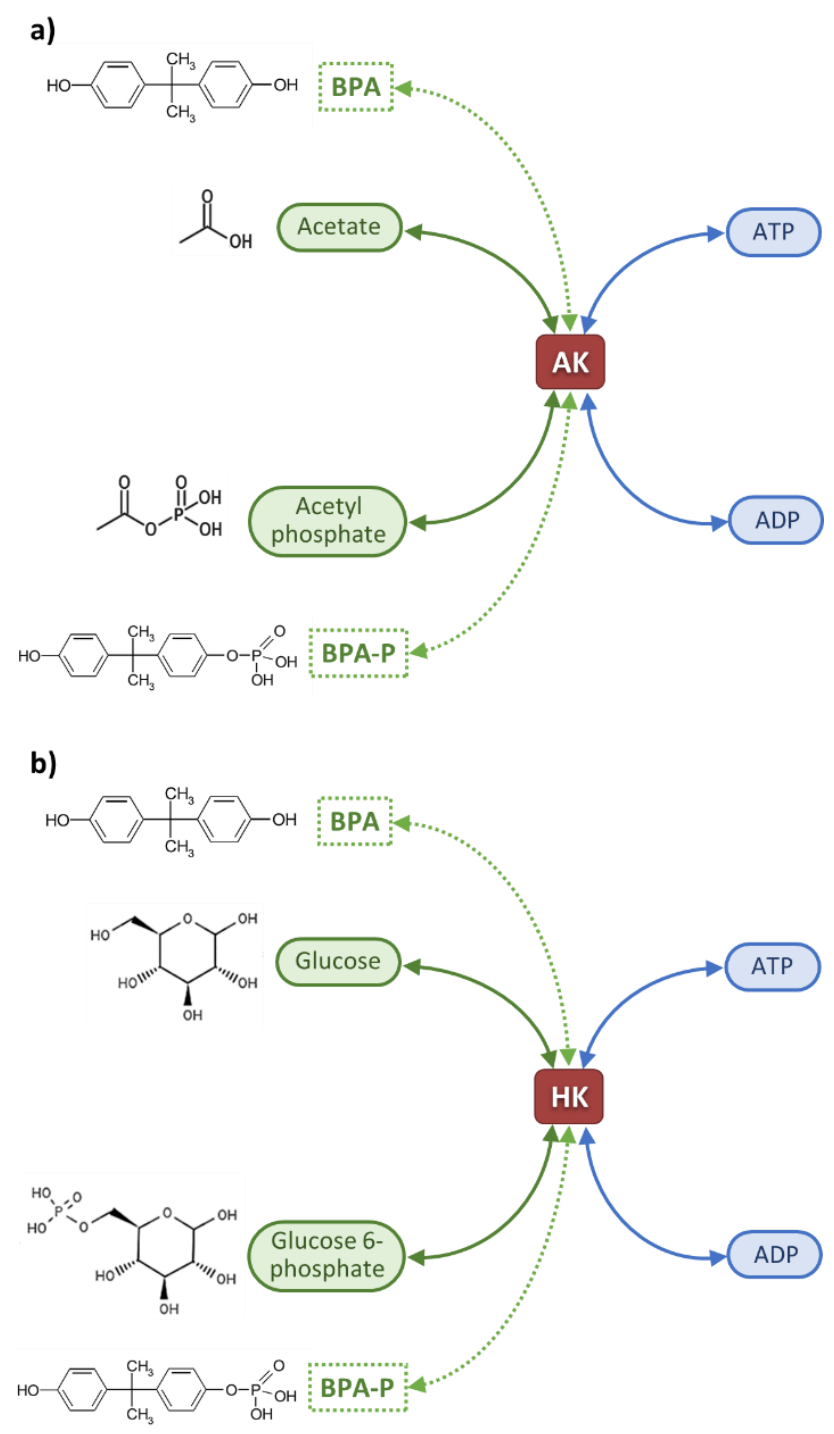

Figure 4. Proposed cometabolic pathway for the reversible transformation of BPA by the enzymes (a) acetate kinase (AK) and (b) hexokinase (HK) during methanogenesis and glycolysis, respectively.

Although we have demonstrated the reversibility of biological reactions with BPA and kinase enzymes, the same behavior could be expected for other OMPs and enzymes. For instance, based on previous findings (Gonzalez-Gil et al., 2017), it can be hypothesized that AK could reversibly transform other OMPs with carboxyl and hydroxyl groups and 
moderate steric hindrance. Likewise, larger compounds that have attached the hexose sugar cladinose, such as roxythromycin, clarithromycin and erythromycin, could undergo a reversible phosphorylation of their hydroxyl groups by HK. In a recent study, Gonzalez-Gil et al. (2019) observed a reversible biotransformation pattern of clarithromycin, erythromycin, citalopram and climbazole in experiments with enzymes extracted from anaerobic sludge. Moreover, apart from Zühlke et al. (2016), there are also some studies reporting reversible biotransformation reactions of OMPs in activated sludge, such as the conversion of SMX into acetyl-SMX (Achermann et al., 2018) and the N-oxidation of tertiary amines as venlafaxine (Gulde et al., 2016). Therefore, reversibility of enzymatic reactions might explain the incomplete biotransformation of several OMPs (once equilibrium with the TP is attained) in STPs.

\section{CONCLUSIONS}

This study contributes to elucidate the enzymatic pathways of the cometabolic transformation of OMPs under anaerobic conditions, which is essential to predict possible TPs and to better understand the removal limitations of OMPs in STPs. We have demonstrated that kinases, namely AK and HK, are likely involved in the reversible transformation of BPA under anaerobic conditions, which may undergo a phosphorylation at its hydroxyl group. These findings support the hypothesis that reversible enzymatic reactions (thermodynamic limitations) could hinder a complete biotransformation of OMPs in biological systems, i.e. once equilibrium is reached between OMPs and TPs respective concentrations, the biotransformation stops. 
Further experiments are needed to confirm the reversible action of other enzymes towards OMPs (and their TPs) that are not fully biotransformed in anaerobic digestion or in other biological systems. Future approaches should bear in mind the role of enzymes on OMP biotransformation to achieve a complete removal via operational strategies. For instance, the addition of specific nutrients could favor particular cometabolic transformation activities towards OMPs or even allow a further transformation of TPs (shifting the chemical equilibrium between OMPs and TPs). This study clearly confirms that efficient and feasible mitigation strategies cannot be developed without understanding the biotransformation pathways of OMPs.

\section{Acknowledgements}

This research was funded by the Spanish Government (AEI) through COMETT project (CTQ2016-80847-R) and by FPU program with a contract (FPU13/01255) and a short research stay grant (EST16/00138). Authors from Universidade de Santiago de Compostela belong to CRETUS Strategic Partnership (AGRUP2015/02) and to Galicia Competitive Research Group (GRC ED431C 2017/29) which are co-funded by FEDER (EU).

\section{REFERENCES}

Achermann, S., Bianco, V., Mansfeldt, C., Vogler, B., Kolvenbach, B.A., Corvini, P.F.-X., Fenner, K., 2018. Biotransformation of Sulfonamide Antibiotics in Activated Sludge: Formation of Pterin-Conjugates Leads to Sustained Risk. Environ. Sci. Technol. 52, 6265-6274.

Allen, S.H., Kellermeyer, R.W., Stjernholm, R.L., Wood, H.G., 1964. Purification and Properties of Enzymes Involved in the Propionic Acid Fermentation. J. Bacteriol. 87, 171-87.

Blair, B., Nikolaus, A., Hedman, C., Klaper, R., Grundl, T., 2015. Evaluating the degradation, sorption, and negative mass balances of pharmaceuticals and personal care products during wastewater treatment. Chemosphere 134, 395-401. 
BRENDA The Comprehensive Enzyme Information System. https://www.brendaenzymes.org/ (accessed 11.14.18).

Canback, B., Andersson, S.G.E., Kurland, C.G., 2002. The global phylogeny of glycolytic enzymes. Proc. Natl. Acad. Sci. U. S. A. 99, 6097-6102.

Cárdenas, M.L., Cornish-Bowden, A., Ureta, T., 1998. Evolution and regulatory role of the hexokinases. Biochim. Biophys. Acta - Mol. Cell Res. 1401, 242-264.

De Vrieze, J., Hennebel, T., Boon, N., Verstraete, W., 2012. Methanosarcina: the rediscovered methanogen for heavy duty biomethanation. Bioresour. Technol. 112, 19.

Feng, J., Gu, Y., Quan, Y., Gao, W., Dang, Y., Cao, M., Lu, X., Wang, Y., Song, C., Wang, S., 2017. Construction of energy-conserving sucrose utilization pathways for improving poly- $\gamma$-glutamic acid production in Bacillus amyloliquefacien. Microb. Cell Fact. 16, 98.

Fernandez-Fontaina, E., Carballa, M., Omil, F., Lema, J.M., 2014. Modelling cometabolic biotransformation of organic micropollutants in nitrifying reactors. Water Res. 65, 371-383.

Ferry, J.G., 2011. Acetate Kinase and Phosphotransacetylase, in: Methods in Methane Metabolism, Part A. Elsevier Inc., pp. 219-231.

Fromm, H.J., Silverstein, E., Boyer, P.D., 1964. Equilibrium and Net Reaction Rates in Relation To the Mechanism of Yeast Hexokinase. J. Biol. Chem. 239, 3645-3652.

Gonzalez-Gil, L., Carballa, M., Lema, J.M., 2017. Cometabolic Enzymatic Transformation of Organic Micropollutants under Methanogenic Conditions. Environ. Sci. Technol. 51, 2963-2971.

Gonzalez-Gil, L., Krah, D., Ghattas, A., Carballa, M., Wick, A., Helmholz, L., Lema, J.M., Ternes, T.A., 2019. Biotransformation of organic micropollutants by anaerobic sludge enzymes. Water Res. 152, 202-214.

Gonzalez-Gil, L., Mauricio-Iglesias, M., Carballa, M., Lema, J.M., 2018a. Why are organic micropollutants not fully biotransformed? A mechanistic modelling approach to anaerobic systems. Water Res. 142, 115-128.

Gonzalez-Gil, L., Mauricio-Iglesias, M., Serrano, D., Lema, J.M., Carballa, M., 2018b. Role of methanogenesis on the biotransformation of organic micropollutants during anaerobic digestion. Sci. Total Environ. 622-623, 459-466.

Gorrell, A., Ferry, J.G., 2007. Investigation of the Methanosarcina thermophila Acetate Kinase Mechanism by Fluorescence Quenching. Biochemistry 46, 14170-14176.

Gulde, R., Anliker, S., Kohler, H.-P., Fenner, K., 2018. Ion trapping of amines in protozoa - a novel removal mechanism for micropollutants in activated sludge. Environ. Sci. Technol. 52, 52-60.

Gulde, R., Meier, U., Schymanski, E.L., Kohler, H.P.E., Helbling, D.E., Derrer, S., Rentsch, D., Fenner, K., 2016. Systematic Exploration of Biotransformation Reactions of Amine-Containing Micropollutants in Activated Sludge. Environ. Sci. Technol. 50, 2908-2920.

Guo, J., Peng, Y., Ni, B.-J., Han, X., Fan, L., Yuan, Z., 2015. Dissecting microbial community structure and methane-producing pathways of a full-scale anaerobic 
reactor digesting activated sludge from wastewater treatment by metagenomic sequencing. Microb. Cell Fact. 14, 33.

Hylemon, P.B., Young, J.L., Roadcap, R.F., Phibbs, P. V., 1977. Uptake and incorporation of glucose and mannose by whole cells of Bacteroides thetaiotaomicron. Appl. Environ. Microbiol. 34, 488-494.

Kotze, J.P., 1969. Glycolytic and Related Enzymes in Clostridial Classification 18, 744 747.

Lack, A., Fuchs, G., 1994. Evidence that phenol phosphorylation to phenylphosphate is the first step in anaerobic phenol metabolism in a denitrifying Pseudomonas sp. Arch. Microbiol. 161, 132-139.

Nakajima, H., Suzuki, K., Imahori, K., 1978. Purification and properties of acetate kinase from Bacillus stearothermophilus. J. Biochem. 84, 193-203.

Rose, I.A., Grunberg-Manago, M., Korey, S.R., Ochoa, S., 1954. Enzymatic phosphorylation of acetate. J. Biol. Chem. 211, 737-756.

Rubin, B.S., 2011. Bisphenol A: an endocrine disruptor with widespread exposure and multiple effects. J. Steroid Biochem. Mol. Biol. 127, 27-34.

Samaras, V.G., Stasinakis, A.S., Thomaidis, N.S., Mamais, D., Lekkas, T.D., 2014. Fate of selected emerging micropollutants during mesophilic, thermophilic and temperature co-phased anaerobic digestion of sewage sludge. Bioresour. Technol. 162, 365-72.

Schmeling, S., Narmandakh, A., Schmitt, O., Gad'on, N., Schühle, K., Fuchs, G., 2004. Phenylphosphate synthase: a new phosphotransferase catalyzing the first step in anaerobic phenol metabolism in Thauera aromatica. J. Bacteriol. 186, 8044-8057.

Sigma Product Information. https://www.sigmaaldrich.com/content/dam/sigmaaldrich/docs/Sigma/Product_Information_Sheet/a6144pis.pdf

Souza, M.A., Ribeiro, M.Z., Pereira Silva, D., Pessoa, A., Vitolo, M., 2002. Effect of pH on the stability of hexokinase and glucose 6-phosphate dehydrogenase. Appl. Biochem. Biotechnol. 98-100, 265-272.

Wijekoon, K.C., McDonald, J.A., Khan, S.J., Hai, F.I., Price, W.E., Nghiem, L.D., 2015. Development of a predictive framework to assess the removal of trace organic chemicals by anaerobic membrane bioreactor. Bioresour. Technol. 189, 391-398.

Xue, W., Wu, C., Xiao, K., Huang, X., Zhou, H., Tsuno, H., Tanaka, H., 2010. Elimination and fate of selected micro-organic pollutants in a full-scale anaerobic/anoxic/aerobic process combined with membrane bioreactor for municipal wastewater reclamation. Water Res. 44, 5999-6010.

Zühlke, M.K., Schlüter, R., Henning, A.K., Lipka, M., Mikolasch, A., Schumann, P., Giersberg, M., Kunze, G., Schauer, F., 2016. A novel mechanism of conjugate formation of bisphenol $\mathrm{A}$ and its analogues by Bacillus amyloliquefaciens: Detoxification and reduction of estrogenicity of bisphenols. Int. Biodeterior. Biodegrad. 109, 165-173. 